\title{
APLIKASI PREDIKSI KELULUSAN MAHASISWA DENGAN METODE LINEAR DISCRIMINANT ANALYSIS
}

\author{
Sulistio \\ PT Adicipta Inovasi Teknologi (AdIns) Jakarta \\ email : sulistio.workmail@gmail.com
}

\begin{abstract}
Abstrak
Aplikasi Prediksi Status Kelulusan adalah sebuah aplikasi yang memprediksi status kelulusan siswa. Aplikasi Prediksi Status Kelulusan Berbasis Web ini dibuat dengan menggunakan metode yang disebut analisis diskriminan linier. Metode ini digunakan untuk mengklasifikasikan objek dari objek lain ke kelas masing-masing dengan menggunakan atributnya. Metode analisis diskriminan linier ini digunakan pada modul prediksi yang memisahkan sekelompok siswa ke kelas masing-masing (lulus tepat waktu atau terlambat) dan kemudian menunjukkan hasilnya kepada pengguna. Data yang digunakan untuk input adalah nilai subjek dari masing-masing siswa. Subjek yang digunakan dalam aplikasi ini dipilih oleh kepala jurusan dengan 22 subjek yang dipilih. Untuk tujuan evaluasi, metode cross validation digunakan, dengan hasil akurasi rata-rata sebesar 97\%.
\end{abstract}

Kata kunci: Koefisien Korelasi, validasi K-Fold Cross, Analisis Diskriminan Linier

\begin{abstract}
Graduation Status Prediction Application is an application that predict graduation status of student. This Web Based Graduation Status Prediction Application is created using method called linear discriminant analysis. This method is used to classified an object from other object to their respective classes by using their attributes. This linear discriminant analysis method is used on predicting module that separate a group of student to their respective classes (passed on time or late) and then showing the result to the user. The data used for input is a subject scores from each student. The subject used in this application is selected by the head major with 22 subject selected currently. For evaluation purpose, $k$-fold cross validation method is used, with the result of average accuracy as big as $97 \%$.
\end{abstract}

Key words : Correlation Coefficient, $K$-Fold Cross validation, Linear Discriminant Analysis

\section{PENDAHULUAN}

Pesatnya kemajuan teknologi di dunia informasi dalam berbagai bidang telah membawa dampak besar bagi umat manusia. Pada bidang pendidikan contohnya, teknologi telah membantu kemudahan proses belajar mengajar bagi pengajar atau pelajar dengan membuat proses kerja menjadi lebih efisien, contohnya pelajar bisa melihat nilai atau mengambil mata 
kuliah dimana saja secara online atau pengajar bisa mengambil dan membawakan materi dengan mudah melalui perangkat keras laptop atau komputer.

Contoh aplikasi akademis yang akan membantu dalam bidang pendidikan adalah aplikasi untuk melakukan prediksi status kelulusan seorang mahasiswa di awal masa perkuliahan, sehingga mahasiswa bisa menyadari hal yang diperlukan untuk membantu dirinya di semester lanjut dan membantu pekerjaan pihak yang berwenang dalam menangani mahasiswa yang dianggap akan mengalami kesulitan untuk lulus tepat waktu.

Dari hasil Tanya jawab diketahui bahwa untuk sekarang, belum ada sistem yang mengurus tentang prediksi kelulusan mahasiswa. Di fakultas teknologi informasi universitas tarumanagara, khususnya Penilaian mahasiswa yang kira-kira perlu mendapat bimbingan dilakukan dengan cara melihat jumlah IPK dan SKS yang dapat diambil mahasiswa di semester empat. Jika IPK dinilai terlalu rendah (dua ke bawah) dan SKS yang dapat diambil 10 atau kurang, maka mahasiswa akan dipanggil untuk menanyakan penyebab dan kesulitannya berkuliah. Setelah itu mahasiswa akan diberi solusi atau sugesti yang dapat membantunya.

Untuk itu dibuatlah sebuah aplikasi prediksi kelulusan mahasiswa yang dibuat untuk Dosen Ketua Jurusan Universitas Tarumanagara yang akan berfungsi untuk memprediksi status kelulusan mahasiswa (lulus tepat waktu atau lulus tidak tepat waktu) berdasarkan nilai mahasiswa dalam mata kuliah yang dianggap sulit dan/atau penting di semester 1 sampai 4 sehingga dosen ketua jurusan bisa mengambil keputusan dengan lebih cepat dan akurat. Aplikasi prediksi kelulusan ini akan menggunakan metode Linear Discriminant Analysis yaitu sebuah metode yang menggunakan nilai dari beberapa variable bebas untuk menentukan kecenderungan masuknya suatu objek ke dalam satu kelompok (variable terikat) yang telah ditentukan yaitu lulus tepat waktu dan tidak tepat waktu. Nama mahasiswa kemudian ditampilkan dengan prediksi dan skor determinan yang didapat dari proses perhitungan fungsi diskriminan. Hal ini diharapkan bisa mempermudah proses prediksi kelulusan untuk mahasiswa yang mengalami masalah dalam mengikuti beberapa pembelajaran, sehingga pihak fakultas bisa membantu dengan memanggil mahasiswa bersangkutan untuk keperluan konseling atau pencarian solusi.

\section{DASAR TEORI}

\subsection{Statistical Classification}

Statistical classification atau sering juga disebut sebagai classification adalah sebuah cara atau metode untuk mengidentifikasi kemana sebuah objek data dikelompokkan. Sebagai contoh adalah klasifikasi email ke dalam kategori spam atau bukan spam, mahasiswa ke dalam kategori lulus tepat waktu, atau tidak tepat waktu, dan sebagainya. Classification juga bisa digunakan untuk membangun sebuah model prediktif untuk memprediksi objek baru [1]. yang masuk ke dalam set data atau objek. Dalam statistical classification biasanya, tiap observasi dari individual atau objek baru akan dianalisa ke dalam suatu set variabel yang bisa dijelaskan (explanatory variable) atau fitur. Nilai dari fitur ini bisa berupa kategori (seperti golongan darah $\mathrm{A}, \mathrm{B}, \mathrm{AB}$, atau $\mathrm{O}$ ), urutan/ordinal (seperti besar, kecil, atau sedang), atau berupa angka (bilangan bulat atau real). Ada juga classifier yang bekerja dengan melakukan perbandingan similaritas observasi lalu dan sekarang. Salah satu cara untuk melakukan classification adalah dengan menggunakan classifier algorithm.

\subsubsection{Classifier Algorithm}

Classifier algorithm atau disebut juga Classification algorithm dan classifier merupakan algoritma yang banyak dipakai untuk keperluan klasifikasi pada bidang ilmu machine learning 
atau statistik. Classification algorithm biasanya digunakan sebagai metode perhitungan untuk melakukan prediksi data baru dengan karakteristik data lama [2]. Classifier algorithm juga biasanya merujuk kepada rumus atau fungsi matematika yang juga mempunyai kemampuan prediksi dengan mengklasifikasi data baru ke dalam kelas tertentu. Beberapa contoh classifier algorithm adalah linear classifier, support vector machine, quadratic classifier, kernel estimation, boosting, decision tree, neural networks, dan learning vector quantization. Semua algoritma klasifikasi mempunyai keuntungan dan kerugian masing - masing, tergantung dari macam - macam factor seperti tipe data set, jumlah kelas dan lain - lain.

\subsubsection{Linear Classifier}

Pada statistical classification, target atau objektif dari klasifikasi adalah menentukan atau mengidentifikasikan kemana sebuah objek dimasukkan dalam beberapa grup atau kelas. Hal ini dilakukan dengan menggunakan kombinasi linear dari beberapa karakteristik atau fitur sebuah objek yang diolah menjadi linear predictor function untuk setiap kelas yang ada. Setelah itu objek baru akan ditentukan untuk masuk ke kelas tertentu berdasarkan hasil skor dengan cara memasukkan karakteristik objek baru ke dalam fungsi predictor. Nilai fungsi yang didapat dari proses klasifikasi ini akan menentukan kelas dari objek setelah diinterpretasi. Salah satu keunggulan dari linear classifier adalah kecepatannya dalam melakukan klasifikasi terutama untuk objek yang hanya mempunyai dua kelas. Linear classifier bisa dicari dengan menggunakan generative model dan discriminative model, yang membedakan model generative dan discriminative adalah prosedur training yang digunakan untuk mencari fungsi diskriminan dan bagaimana hasil skor dari fungsi diskriminan tersebut di interpretasikan. Contoh algoritma yang digunakan dalam discriminative model adalah metode linear discriminant analysis.

\subsubsection{Correlation}

Correlation atau sering juga disebut correlation coefficient (koefisien korelasi) adalah nilai yang digunakan untuk mengukur relasi antara dua pasang set data. Nilai dari korelasi ini bisa dikategorikan sebagai berikut :

- Korelasi positif - jika satu variabel naik, maka variabel lainnya juga akan ikut naik, dan begitupun sebaliknya;

- Korelasi negative - jika satu variabel naik, maka variabel lainnya turun, dan begitupun sebaliknya;

- Tidak ada Korelasi - kenaikan variabel tidak mempengaruhi variabel lainnya sama sekali.

Korelasi positif bisa di kelompokkan lagi menurut jumlah nilainya sebagai berikut:

- $\quad-1.00$ : relasi linear negatif sempurna;

- $\quad-0.99$ sampai -0.70 : relasi linear negatif kuat;

- $\quad-0.69$ sampai -0.50 : relasi linear negatif sedang;

- $\quad-0.49$ sampai -0.01 : relasi linear negatif lemah;

- 0 : tidak ada relasi linear.

- 0.01 sampai 0.49 : relasi linear positif lemah;

- 0.50 sampai 0.69 : relasi linear positif sedang;

- 0.70 sampai 0.99 : relasi linear positif kuat;

- 1.0 : relasi linear positif sempurna.

Langkah menghitung korelasi koefisien adalah sebagai berikut :

1. Hitung total baris kolom $\mathrm{x}$ atau kolom $\mathrm{y}(n)$

2. Hitung total dari nilai kuadrat pada kolom $\mathrm{x}\left(\sum x^{2}\right)$ 
3. Hitung total dari nilai kuadrat pada kolom y $\left(\sum y^{2}\right)$

4. Hitung kuadrat dari nilai total pada kolom $\mathrm{x}\left(\sum x\right)^{2}$

5. Hitung kuadrat dari nilai total pada kolom y $\left(\sum y\right)^{2}$

6. Hitung total dari nilai $\mathrm{x}$ dikali $\mathrm{y}\left(\sum x y\right)$

7. Hitung $S_{x x}=\sum x^{2}-\frac{\left(\sum x\right)^{2}}{n}$

8. Hitung $S_{y y}=\sum y^{2}-\frac{\left(\sum y\right)^{2}}{n}$

9. Hitung $S_{x y}=\sum x y-\frac{\left(\sum x\right)\left(\sum y\right)}{n}$

10. Hitung koefisien korelasi dengan rumus $\hat{p}=\frac{S_{x y}}{\sqrt{S_{x x} S_{y y}}}$

2.1.4. Linear Discriminant Analysis

Linear discriminant analysis adalah generalisasi dari Fisher linear discriminant yang diciptakan oleh Ronald A. Fisher pada tahun 1936 untuk melakukan berbagai pengukuran untuk masalah Taxonomi. Linear discriminant analysis sedikit berbeda dari fisher linear discriminant dimana linear discriminant analysis mengasumsikan variabel yang digunakan berdistribusi normal dan mempunyai kovarians dengan kelas yang sama. Tujuan dari linear discriminant analysis (LDA) adalah mengklasifikasikan objek ke dalam beberapa kelas berdasarkan fitur yang menggambarkan objek tersebut, di dalam linear discriminant analysis objek mempunyai dua variable yaitu variable kelas/terikat (dependent variable) dan variable atribut/bebas (independent variable), variable terikat mempunyai ikatan dengan variable bebas yang yang menggambarkan variable tersebut. Variable bebas nantinya akan digunakan untuk menentukan kombinasi linear dari objek tersebut. LDA bekerja dengan menggunakan analisa matriks penyebaran yang bertujuan menemukan proyeksi optimal sehingga dapat memproyeksikan data input pada ruang dengan dimensi yang lebih kecil dimana semua pola (pattern) dapat dipisahkan semaksimal mungkin [3]. Dalam LDA variable dependent merupakan kelas dari object yang biasanya mempunyai nilai nominal / nama dari kelas (lulus/tidak lulus) dan variable independent merupakan fitur yang menggambarkan object tersebut biasanya bernilai skalar. Sebelum melakukan prediksi, LDA membutuhkan fase training untuk menentukan fungsi diskriminan. Fase training ini membutuhkan objek yang telah terklasifikasi beserta sejumlah variabel fitur/independen variable. Langkah dalam menghitung fase training dalam LDA adalah sebagai berikut :

1. Kelompokkan training data ke dalam matriks sejumlah kelasnya dinotasikan dengan $X_{i}$ Keterangan :

$\mathrm{i}=$ jumlah kelas.

2. Hitung matriks rata-rata dari tiap kelas $\left(\mu_{i}\right)$

3. Hitung rata-rata global dari keseluruhan data $(\mu)$

4. Hitung mean corrected data $\left(X_{i}^{0}\right)$ dengan mengurangkan setiap nilai pada $X_{i}$ dengan nilai rata-rata global $(\mu)$

5. Hitung covariance matriks ( $\left.C_{i}\right)$ dari masing-masing $X_{i}$ dengan rumus :

$C_{i}=\frac{\left(x_{i}^{0}\right)^{T} x_{i}^{0}}{n_{i}}(5)$

$n_{i}=$ banyak baris pada grup $X_{i}$

Keterangan:

6. Hitung nilai covariance global matriks $(C)$ dengan rumus :

$C=\frac{1}{N} \sum_{i=1}^{g} n_{i} c_{i}(6)$

Keterangan:

$\mathrm{N}=$ jumlah baris dari keseluruhan data. 
7. Setelah itu hitung invers dari matriks $\mathrm{C}\left(\mathrm{C}^{-1}\right)$.

8. Cari peluang dari tiap kelas $\left(P_{i}\right)$.

9. Dengan begitu kita bisa menghitung fungsi diskriminan $\left(f_{i}\right)$ Dengan rumus :

$f_{i}=\mu_{i} C^{-1} X_{k}^{T}-\frac{1}{2} \mu_{i} C^{-1} \mu_{i}^{T}+$

$\ln \left(p_{i}\right)(7)$

10. Setelah $f_{i}$ setiap kelas diketahui, akurasi fungsi diskriminan bisa dilakukan dengan melakukan pemetaan ulang tiap grup dalam training data dengan fungsi diskriminan $f_{i}$

11. Objek dari data training akan masuk ke dalam kelas tergantung dari nilai maksimum $f_{i}$

Setelah rumus diskriminan di ketahui dan di uji akurasinya, maka fase training bisa dinyatakan selesai, dan fungsi dikriminan ini sudah bisa digunakan untuk mengklasifikasikan objek baru ke dalam kelas yang ditentukan.

Dengan menghitung $X_{k}^{T}$ dari objek baru dan kemudian memasukkannya ke dalam fungsi diskriminan masing - masing kelas. Objek baru akan di kelompokkan ke dalam kelas yang diwakili oleh fungsi diskriminan yang mempunyai nilai terbesar.

\subsubsection{Cross validation}

Cross validation merupakan teknik yang digunakan untuk melakukan evaluasi sebuah model atau fungsi. Proses validasi menggunakan cross validation dinilai lebih baik daripada evaluasi biasa, karena evaluasi biasa tidak memberikan indikasi seberapa baik sebuah model yang di training bisa melakukan prediksi atau perhitungan sebuah data set baru yang belum pernah digunakan. Cara untuk mengatasi masalah tersebut adalah dengan hanya mengguakan sebagian data yang digunakan untuk training sebagai sample set dan sisanya sebagai training set. Hal ini bisa membantu dalam mengukur performa sebuah model terhadap data trainingnya sendiri. Hal tersebut adalah ide kasar dari bermacam - macam variasi cross validation.

\subsubsection{K-Fold Cross validation}

$K$-Fold Cross Validation merupakan salah satu variasi dari cross validation. Cara perhitungan $K$-fold cross validation sama dengan ide kasar dari cross validation, namun sebelum validasi dilakukan, data set yang digunakan akan dibagi terlebih dahulu kedalam $k$ subset, yang kemudian dihitung persentase keberhasilan model yang dibuat dari subset $k-1$ dalam memprediksi salah satu subset $k$. Proses ini diulang sebanyak $k$ kali untuk menentukan rata rata keberhasilan beserta standar deviasi dari keberhasilan perhitungan model. Keunggulan dari model ini dibandingkan dengan model cross validation lainnya adalah, tidak peduli bagaimana data dibagi, setiap subset $k$ akan divalidasi sebanyak satu kali dan juga akan dijadikan data training sebanyak $k-1$ kali. Sehingga hasil evaluasi menjadi lebih baik, meskipun perhitungan menjadi lebih lambat karena pengulangan sebanyak $k$.

\section{PEMBAHASAN}

Pengujian data dilakukan ketika pengujian modul selesai dilakukan. Pengujian data ini dilakukan dengan menggunakan data training dari pihak Fakultas Teknologi Informasi Universitas tarumanagara dengan jumlah data sebanyak 462 mahasiswa dari angkatan 20082012 yang telah di ketahui status kelulusannya dengan cara melihat pengambilan skripsi pada semester 8 atau 7, jika mahasiswa mengambil skripsi lewat dari semester tersebut, maka mahasiswa itu dinyatakan tidak lulus tepat waktu, dan begitupun sebaliknya jika mahasiswa 
mengambil skripsi pada semester 8 atau 7, maka mahasiswa dianggap lulus tepat waktu. Informasi data sampel dan data training untuk pengujian dilakukan menggunakan data yang didapat dari pihak Universitas Tarumanagara. Pengujian data ini dilakukan dengan menggunakan metode $k$-fold cross validation, yaitu proses validasi data dengan melakukan prediksi terhadap subset dari dataset yang telah dibagi sebanyak $k$.

Cara penentuan skor prediksi didapat dengan menggunakan metode analisa diskriminan. Sebelum menentukan metode diskriminan, akan dilakukan terlebih dahulu perhitungan korelasi antara masing masing mata kuliah dengan status kelulusan, hal ini dilakukan karena ada beberapa mata kuliah yang sebenarnya bisa diwakilkan oleh mata kuliah lainnya tanpa mengurangi akurasi fungsi diskriminan. Mata kuliah yang digunakan antara lain adalah Kalkulus 1, Algoritma 1, Manajemen Organisasi, Pengenalan Komputer, Matematika Diskrit, Statistika 1, Sistem Informasi, Algoritma 2, Sistem Digital, Sistem Operasi, Interaksi Manusia dan Komputer, Aljabar Linear, Fisika Mekanika, Analisis Algoritma, Statistika 2, Pengantar Intelegensia Buatan, Teori Graf, Teknik Simulasi, Kalkulus 2, Struktur Data, Jaringan Komputer, dan Pemrograman GUI dengan NET.

Berikut adalah tabel korelasi mata kuliah dengan status kelulusan Mahasiswa :

Tabel 1. Korelasi tiap mata kuliah dengan status kelulusan

\begin{tabular}{|l|l|}
\hline Mata Kuliah & Skor Korelasi \\
\hline KALKULUS I & 0.5445032135827 \\
\hline $\begin{array}{l}\text { ALGORIT.\& PEMROGR.C++ } \\
\text { DSR }\end{array}$ & 0.50358538061008 \\
\hline MANAJEMEN \& ORGANISASI & 0.44074879549712 \\
\hline PENGENALAN KOMPUTER & 0.46778183193119 \\
\hline MATEMATIKA DISKRIT & 0.58069515420779 \\
\hline STATISTIKA I & 0.52758493961934 \\
\hline SISTEM INFORMASI & 0.39699084456906 \\
\hline $\begin{array}{l}\text { ALGORIT.\& } \\
\text { PEMROGR.C++LANJ }\end{array}$ & 0.46461606323931 \\
\hline SISTEM DIGITAL & 0.62480328040473 \\
\hline SIS.OPERASI \& PRAK.LINUX & 0.5300054892236 \\
\hline $\begin{array}{l}\text { INTER. MANUSIA \& } \\
\text { KOMPUTER }\end{array}$ & 0.46145780058079 \\
\hline ALJABAR LINIER & 0.54769188568976 \\
\hline FISIKA MEKANIKA & 0.54207782307272 \\
\hline ANALISIS ALGORITMA & 0.5781577210263 \\
\hline STATISTIK II & 0.58157295324348 \\
\hline $\begin{array}{l}\text { PENG. INTELEGENSI } \\
\text { BUATAN }\end{array}$ & 0.48817652769498 \\
\hline TEORI GRAF & 0.51350574091775 \\
\hline TEKNIK SIMULASI & 0.55029620333068 \\
\hline
\end{tabular}




\begin{tabular}{|l|l|}
\hline STRUKTUR DATA & 0.578078284129 \\
\hline JAR.KOMP.I \& PRAK. LAN & 0.60236288538581 \\
\hline $\begin{array}{l}\text { PEMROGRAMAN GUI DGN } \\
\text { NET }\end{array}$ & 0.43156533069066 \\
\hline KALKULUS II & 0.567128169721 \\
\hline
\end{tabular}

Berdasarkan perhitungan korelasi, mata kuliah yang akan dipilih adalah mata kuliah dengan nilai korelasi $>=0.5$ atau korelasi positif sedang yaitu Kalkulus 1, Algoritma 1, Matematika Diskrit, Statistika 1, Sistem Digital, Sistem Operasi, Aljabar Linear, Fisika Mekanika, Analisis Algoritma, Statistika 2, Pengantar Intelegensia Buatan, Teori Graf, Kalkulus 2, Struktur Data, dan Jaringan Komputer.

Setelah melakukan perhitungan korelasi, $k$-fold cross validation untuk fungsi diskriminan bisa dihitung, Hasil validasi $k$-fold cross validation fungsi diskriminan dengan nilai tengah mean yaitu data akurasi setiap iterasi beserta mean akurasi keberhasilan dan standar deviasinya bisa dilihat pada Tabel berikut.

Tabel 1. Persentase kebenaran dari $k$-fold cross validation dengan $\mathrm{K}=10$ dan nilai tengah mean

\begin{tabular}{|l|l|}
\hline Iterasi & persentase kebenaran \\
\hline 1 & 0.98076923076923 \\
\hline 2 & 0.97596153846154 \\
\hline 3 & 0.98076923076923 \\
\hline 4 & 0.97355769230769 \\
\hline 5 & 0.97596153846154 \\
\hline 6 & 0.97115384615385 \\
\hline 7 & 0.96394230769231 \\
\hline 8 & 0.98557692307692 \\
\hline 9 & 0.96634615384615 \\
\hline 10 & 0.97836538461538 \\
\hline
\end{tabular}

Dari hasil evaluasi dengan menggunakan $k$-fold cross validation di atas, bisa di ketahui bahwa model diskriminan yang dibuat dengan data angkatan 2008-2012 yang status kelulusannya telah di ketahui berdasarkan waktu pengambilan skripsi (semester 8 ke bawah tepat waktu, jika lewat dari 8 semester berarti tidak tepat waku) mampu memprediksi status kelulusan mahasiswa dengan rata-rata tingkat akurasi yang tinggi yaitu 0.97524038461538 dan dengan standar deviasi yang rendah yaitu sebesar 0.0009882117688026 atau bisa diartikan variasi dari tiap akurasi tidak berbeda jauh untuk masing masing pengujian. Sehingga model ini diperkirakan bisa digunakan untuk memprediksi status kelulusan mahasiswa dengan cukup tepat.

Selain menggunakan $k$-fold cross validation, dilakukan juga evaluasi terhadap kondisi sebenarnya. Sebelum melakukan evaluasi, data terlebih dahulu diambil secara acak dari data mahasiswa angkatan 2008-2012, akan tetapi diambil lebih dominan angkatan yang telah lulus semua yaitu angkatan 2008-2011. Setelah itu barulah dilakukan prediksi dengan fungsi diskriminan yang telah dibuat. 
Computatio: Journal of Computer Science and Information Systems Volume 1 Tahun 2017

Berkut adalah tabel yang menampilkan hasil test dengan data yang sebenarnya

Tabel 3. Tabel evaluasi hasil prediksi kelulusan terhadap data yang sebenarnya

\begin{tabular}{|c|c|c|c|c|}
\hline NIM & F1(TP) & F2(TTP) & Prediksi & $\begin{array}{l}\text { Status } \\
\text { Asli }\end{array}$ \\
\hline $53508 x x$ & 5.760731 & 4.771442 & $\mathrm{TP}$ & $\mathrm{TP}$ \\
\hline $53508 x x$ & 3.149358 & 2.568873 & TP & TP \\
\hline $53508 x x$ & 3.24939 & 2.439733 & TP & TP \\
\hline $53508 x x$ & 4.46365 & 3.835099 & TP & TP \\
\hline $53508 x x$ & 3.447809 & 2.515659 & TP & TP \\
\hline $53508 x x$ & 4.124697 & 3.993859 & TP & TP \\
\hline $53508 x x$ & 3.008789 & 3.757178 & TTP & TTP \\
\hline $53508 x x$ & 2.97147 & 2.773845 & TP & TP \\
\hline NIM & F1(TP) & F2(TTP) & Prediksi & $\begin{array}{l}\text { Status } \\
\text { Asli }\end{array}$ \\
\hline $53508 x x$ & -4.91711 & -1.1902 & TTP & TTP \\
\hline $53508 x x$ & 2.507236 & 3.512495 & TTP & TTP \\
\hline $53508 x x$ & 3.376343 & 3.107528 & TP & TTP \\
\hline $53508 x x$ & 3.340349 & 2.322289 & TP & TP \\
\hline $53509 x x$ & -4.51249 & -0.79623 & TTP & TTP \\
\hline $53509 x x$ & 8.309802 & 10.69586 & TTP & TTP \\
\hline $53509 x x$ & -4.36566 & -0.70433 & TTP & TTP \\
\hline $53509 x x$ & 4.545343 & 7.230996 & TTP & TTP \\
\hline $53509 x x$ & 3.033441 & 3.668657 & TTP & TTP \\
\hline $53509 x x$ & 4.069885 & 4.155745 & TTP & TTP \\
\hline $53509 x x$ & 4.05622 & 5.0092 & TTP & TTP \\
\hline $53509 x x$ & 1.957056 & 1.708298 & $\mathrm{TP}$ & $\mathrm{TP}$ \\
\hline $53509 x x$ & 5.458577 & 6.435361 & TTP & TTP \\
\hline $53509 x x$ & -3.35261 & 0.249826 & TTP & TTP \\
\hline $53509 x x$ & 4.500802 & 3.599059 & TP & TP \\
\hline $53509 x x$ & -0.95687 & 1.602285 & TTP & TTP \\
\hline $53509 x x$ & 4.566377 & 7.602546 & TTP & TTP \\
\hline $53509 x x$ & 6.988382 & 7.003502 & TTP & TP \\
\hline $53509 x x$ & 0.472376 & -0.33456 & TP & TTP \\
\hline $53509 x x$ & 2.431116 & 3.488023 & TTP & TTP \\
\hline $53509 x x$ & -5.20836 & -1.90614 & TTP & TTP \\
\hline $53509 x x$ & 5.675335 & 5.626672 & TP & TP \\
\hline $53509 x x$ & 1.550949 & 2.219866 & TTP & TTP \\
\hline $53509 x x$ & 5.851963 & 4.31312 & TP & TP \\
\hline $53509 x x$ & -0.39618 & 2.462287 & TTP & TTP \\
\hline $53510 x x$ & 6.805087 & 5.505548 & TP & TP \\
\hline $53510 x x$ & 4.804802 & 5.648488 & TTP & TTP \\
\hline $53510 x x$ & 1.709683 & 2.935271 & TTP & TTP \\
\hline $53510 x x$ & 6.802169 & 6.197417 & TP & TP \\
\hline $53510 x x$ & 3.500307 & 3.683374 & TTP & TP \\
\hline $53510 x x$ & -2.9626 & 0.608214 & TTP & TTP \\
\hline $53510 x x$ & 6.561163 & 5.253956 & TP & TP \\
\hline $53510 x x$ & 6.851601 & 6.050481 & TP & TP \\
\hline $53510 x x$ & 3.244781 & 6.087617 & TTP & TTP \\
\hline $53510 x x$ & 2.931207 & 2.502388 & TP & TP \\
\hline $53510 x x$ & 3.505926 & 3.576274 & TTP & TTP \\
\hline $53510 x x$ & -2.23736 & 1.728325 & TTP & TTP \\
\hline $53510 x x$ & 3.895822 & 3.446088 & $\mathrm{TP}$ & TTP \\
\hline
\end{tabular}


Computatio: Journal of Computer Science and Information Systems Volume 1 Tahun 2017

\begin{tabular}{|c|c|c|c|c|}
\hline $53510 x x$ & 4.275853 & 3.472616 & $\mathrm{TP}$ & $\mathrm{TP}$ \\
\hline 53510xx & 4.70442 & 3.946283 & TP & TP \\
\hline $53510 x x$ & 6.802169 & 6.197417 & TP & TP \\
\hline $53510 x x$ & 3.500307 & 3.683374 & TTP & $\mathrm{TP}$ \\
\hline $53510 x x$ & -2.9626 & 0.608214 & TTP & TTP \\
\hline $53510 x x$ & 6.561163 & 5.253956 & $\mathrm{TP}$ & $\mathrm{TP}$ \\
\hline $53510 x x$ & 6.851601 & 6.050481 & TP & $\mathrm{TP}$ \\
\hline $53510 \mathrm{xx}$ & 3.244781 & 6.087617 & TTP & TTP \\
\hline $53511 x x$ & 1.116941 & 1.11778 & TTP & TTP \\
\hline $53511 x x$ & 5.629925 & 7.209402 & TTP & TTP \\
\hline 53508xx & 5.760731 & 4.771442 & TP & $\mathrm{TP}$ \\
\hline $53508 \mathrm{xx}$ & 3.149358 & 2.568873 & TP & $\mathrm{TP}$ \\
\hline $53508 \mathrm{xx}$ & 3.24939 & 2.439733 & $\mathrm{TP}$ & $\mathrm{TP}$ \\
\hline NIM & F1(TP) & F2(TTP) & Prediksi & $\begin{array}{l}\text { Status } \\
\text { Asli } \\
\end{array}$ \\
\hline $53508 \mathrm{xx}$ & 4.46365 & 3.835099 & TP & TP \\
\hline 53508xx & 3.447809 & 2.515659 & TP & $\mathrm{TP}$ \\
\hline $53508 \mathrm{xx}$ & 4.124697 & 3.993859 & TP & TP \\
\hline $53508 \mathrm{xx}$ & 3.008789 & 3.757178 & TTP & TTP \\
\hline 53508xx & 2.97147 & 2.773845 & TP & TP \\
\hline 53508xx & 4.966252 & 4.346115 & TP & TP \\
\hline $53508 \mathrm{xx}$ & -4.91711 & -1.1902 & TTP & TTP \\
\hline $53511 x x$ & -3.85737 & -0.2147 & TTP & TTP \\
\hline $53511 x x$ & 3.551339 & 3.257084 & TP & $\mathrm{TP}$ \\
\hline $53511 \mathrm{xx}$ & 2.888152 & 4.052451 & TTP & TTP \\
\hline $53511 \mathrm{xx}$ & 0.903208 & 0.839834 & $\mathrm{TP}$ & $\mathrm{TP}$ \\
\hline $53511 x x$ & 4.059372 & 4.109303 & TTP & $\mathrm{TP}$ \\
\hline $53511 x x$ & 4.059372 & 4.109303 & TTP & $\mathrm{TP}$ \\
\hline 53511xx & 3.511761 & 3.351048 & TP & TP \\
\hline $53511 x x$ & 4.227187 & 4.105138 & TP & TTP \\
\hline $53511 x x$ & 2.589827 & 3.168644 & TTP & TTP \\
\hline $53511 x x$ & 4.749142 & 3.709915 & $\mathrm{TP}$ & $\mathrm{TP}$ \\
\hline $53511 x x$ & 5.891646 & 6.347312 & TTP & $\mathrm{TP}$ \\
\hline 53511xx & 3.048957 & 3.248125 & TTP & TTP \\
\hline 53511xx & 6.798641 & 5.445576 & TP & TP \\
\hline 53511xx & 6.648056 & 5.322937 & $\mathrm{TP}$ & $\mathrm{TP}$ \\
\hline $53511 x x$ & 6.985704 & 5.657514 & $\mathrm{TP}$ & $\mathrm{TP}$ \\
\hline $53511 x x$ & 5.925863 & 5.03334 & $\mathrm{TP}$ & $\mathrm{TP}$ \\
\hline $53512 x x$ & 6.226661 & 6.145351 & $\mathrm{TP}$ & $\mathrm{TP}$ \\
\hline $53512 x x$ & 5.153755 & 4.195419 & $\mathrm{TP}$ & TTP \\
\hline $53512 x x$ & 4.776775 & 3.603578 & TP & TP \\
\hline $53512 x x$ & 7.482203 & 7.017821 & TP & $\mathrm{TP}$ \\
\hline $53512 x x$ & 7.031486 & 5.932544 & TP & TP \\
\hline $53512 x x$ & 3.918742 & 4.806909 & TTP & TTP \\
\hline $53512 x x$ & 6.15393 & 5.063247 & $\mathrm{TP}$ & $\mathrm{TP}$ \\
\hline $53512 x x$ & 2.266704 & 3.190072 & TTP & TP \\
\hline $53512 x x$ & 4.671987 & 4.154253 & $\mathrm{TP}$ & $\mathrm{TP}$ \\
\hline $53512 x x$ & 6.688716 & 5.526372 & $\mathrm{TP}$ & $\mathrm{TP}$ \\
\hline $53512 x x$ & 5.45342 & 5.834071 & TTP & TTP \\
\hline $53512 x x$ & 5.934676 & 4.509174 & $\mathrm{TP}$ & $\mathrm{TP}$ \\
\hline $53512 x x$ & 7.334315 & 6.64871 & $\mathrm{TP}$ & $\mathrm{TP}$ \\
\hline $53512 x x$ & 6.694664 & 6.062424 & TP & TP \\
\hline 53512xx & 5.595951 & 4.277811 & TP & TP \\
\hline
\end{tabular}




\begin{tabular}{|l|l|l|l|l|}
\hline $53512 \mathrm{xx}$ & 3.343784 & 4.068016 & TTP & TTP \\
\hline $53512 \mathrm{xx}$ & 5.538413 & 4.270797 & TP & TP \\
\hline
\end{tabular}

Keterangan: *TP : Lulus tepat waktu, TTP : Lulus tidak tepat waktu

Jumlah individu yang digunakan untuk proses testing sebanyak 100 dengan kegagalan prediksi sebanyak 7 individu (baris dengan shading gelap) sehingga kemungkinan terjadi kegagalan sebesar 7/100 atau 0.07 dengan demikian persentase keberhasilan adalah 93\%.

\section{KESIMPULAN}

1. Aplikasi ini dapat melakukan prediksi status kelulusan mahasiswa yang cukup akurat yaitu lebih dari $90 \%$ untuk evaluasi terhadap kondisi sebenarnya, maupun rata rata dari tiap iterasi $k$-fold cross validation.

2. Aplikasi ini telah dapat berjalan dengan baik sesuai dengan perancangan dan kebutuhan prediksi status mahasiswa.

\section{DAFTAR PUSTAKA}

[1] Minsoo Kim, "Statistical Classification", Pomona College Paper, 2010 pg. 5

[2] Patrick Ozer, "Data Mining Algorithms for Classification", BSc Thesis Artificial Intelligence, 2008 pg. 2

[3] Ghazali, Eko K. Subha, Galuh M., M. Burhannudin, M.Izzun Niam, “Aplikasi Kematangan Tomat Berdasarkan Warna dengan Metode Linear Discriminant Analysis (LDA)", Universitas Brawijaya, Malang, 2013 Pg. 2 